\title{
THE TIMING AND VARIATION OF PRE- IMPLANTATION EVENTS IN THE MOUSE
}

\author{
B. J. RESTALL AND B. M. BINDON \\ Department of Veterinary Physiology, University of Sydney, Sydney, N.S.W., \\ Australia
}

(Received 25th Fune 1970)

\begin{abstract}
Summary. Spacing of zygotes, loss of the zona pellucida, and appearance of localized areas of increased vascular permeability at the implantation sites in the uterus were observed in groups of mice examined at 2-hr intervals from 10.00 hours to midnight on Day 4 of pregnancy, and at $02.00,08.30$ and 15.00 hours on Day 5. All the events examined had a 6- to 8-hr variation in their time of occurrence.

Studies of interrelationships between the zygote and the uterus require a precise knowledge of the timing, variation and sequence of the events leading up to implantation in any one species. Previous studies of preimplantation phenomena in the rodent have been based on relatively small numbers of animals examined at irregular intervals during the periods of interest.
\end{abstract}

In the present study, mice of the QS strain, aged 8 to 10 weeks and weighing 24 to $28 \mathrm{~g}$, were maintained under uniform environmental conditions at temperatures of 22 to $25^{\circ} \mathrm{G}$ and lighting from 06.00 to 18.00 hours. The day of appearance of the vaginal plug was designated Day 1 of pregnancy. Mice were allocated at random to the various groups which were killed at 2-hr intervals from 10.00 hours on Day 4 of pregnancy until 02.00 hours on Day 5, and at 08.30 and 15.00 hours on Day 5 .

Spacing of the zygotes was studied by preparing serial longitudinal $12-\mu$ sections of the uteri of ten mice from each group. All sections were examined microscopically for zygotes and maps of the uteri were prepared.

Loss of the zona pellucida was studied by flushing the uteri of twenty mice in each group. Between fifteen and thirty mice, including some of those flushed for egg recovery, were injected with 0 to $0.2 \mathrm{ml}$ of $0.5 \%$ Evans Blue dye $15 \mathrm{~min}$ before killing. The uteri of these mice were examined for the presence of the dye bands characteristic of implantation sites (Psychoyos, 1961).

The results of the various observations are given in Table 1, with details of the numbers of animals used and the numbers of zygotes recovered. Spacing had begun by 10.00 hours on Day 4 in a few cases and had been completed in several mice by 16.00 hours. By 24.00 hours on the same day, all mice examined had spaced zygotes. Loss of the zona began between 14.00 hours and 16.00 hours on Day 4 and few zygotes retained the zona by 02.00 hours on Day 5 . 


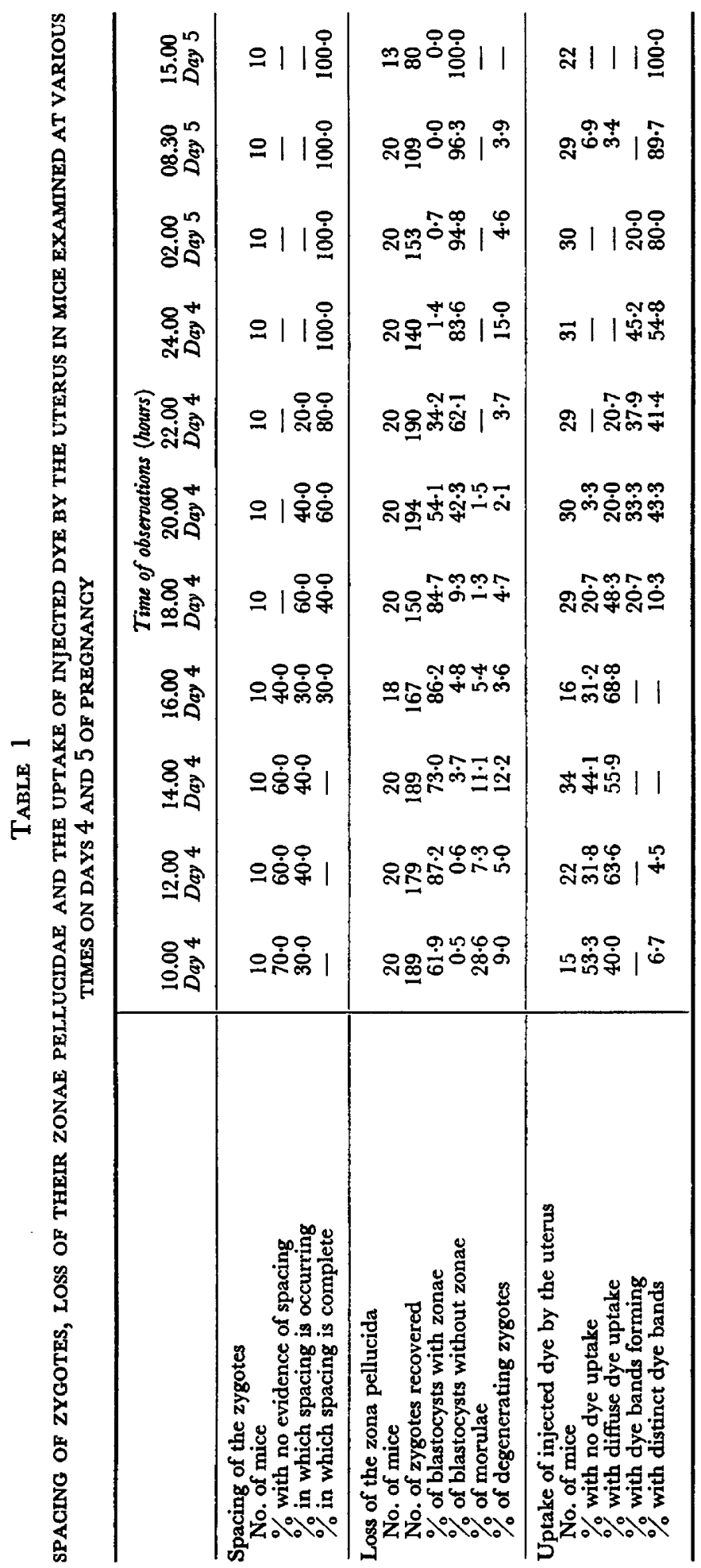


Only a small proportion of mice had discrete dye sites in the uterus before 18.00 hours on Day 4 . By midnight on Day 4 approximately $50 \%$ had dye sites but in some mice, such dye bands were not observed until 15.00 hours on Day 5 .

The mean number of zygotes recovered by flushing fell significantly between 22.00 hours and 24.00 hours on Day 4, which was taken as indicating that the process of attachment had started during this period.

The question arises whether shedding of the zona influences the appearance of dye sites or whether the two are independent. This was tested by classifying those mice for which both attributes were available at 20.00 hours and 22.00 hours on Day 4 . The $2 \times 4$ table of values in Table 2 was subjected to a test of independence, the result of which $\left(\chi_{(3)}^{2}=26.9, P<0.001\right)$ indicates that the events are not independent. A significantly greater proportion of zygotes were without the zona pellucida after dye bands appeared in the uterus, a proportion of the zygotes were zona-free before the first dye bands appeared, suggesting that shedding of the zona pellucida is usually initiated before localized increased permeability changes occur in the uterus.

\section{TABLE 2}

THE RELATIONSHIP BETWEEN LOSS OF THE ZONA PELLUGIDA AND THE APPEARANGE OF DISTINCT DYE BANDS AGROSS THE UTERUS AFTER THE INJEGTION OF EVANS BLUE DYE

\begin{tabular}{l|c|c|c|c}
\hline \multirow{2}{*}{} & \multicolumn{4}{|c}{ Reaction to injected dye } \\
\cline { 2 - 5 } & $\begin{array}{c}\text { Dye bands } \\
\text { absent from uterus }\end{array}$ & \multicolumn{2}{|c}{$\begin{array}{c}\text { Dye bands } \\
\text { present in uterus }\end{array}$} \\
\cline { 2 - 5 } & 20.00 & 22.00 & 20.00 & 22.00 \\
hours & hours & hours & hours \\
\hline$\%$ blastocysts with zonae pellucidae & 65.0 & $50 \cdot 0$ & 35.0 & 29.0 \\
\hline blastocysts without zonae pellucidae & 35.0 & $50 \cdot 0$ & $65 \cdot 0$ & $71 \cdot 0$ \\
\hline
\end{tabular}

Test of independence: $\chi^{2}=26.95$, d.f. $3, P<0.001$.

Before spacing of the zygotes occurred, they were seen to be grouped together in the middle of each horn. In Plate 1, Fig. 1, three spherical blastocysts are shown in a section of the lumen measuring 1 to $2 \mathrm{~mm}$ in length. In Fig. 2, four zygotes are beginning to disperse. Cases were observed of up to eight blastocysts lying adjacent to one another in the horn.

Subsequent spacing occurred equally in both directions from the centre. The zygotes in Figs. 3 and 4 (16.00 to 20.00 hours on Day 4) are of the type found during spacing. Some evidence of expansion is shown by zygotes in Figs. 5 and 6.

The results illustrate the difficulty of localizing any of the pre-implantation phenomena to a particular point in time. The examination of relatively large numbers of mice at 2-hr intervals has shown that spacing, zona loss and development of dye sites may occupy 6 to $8 \mathrm{hr}$ from start to completion in any group of mice. With the exception of the spacing data which have not before been described, these results confirm those of Dickson (1966) and McLaren (1969). 


\section{REFERENCES}

Drckson, A. D. (1966) The form of the mouse blastocyst. F. Anat. 100, 335.

McLaren, A. (1969) Stimulus and response during early pregnancy in the mouse. Nature, Lond. 221, 739.

Psycroyos, A. (1961) Perméabilité capillaire et décidualization utérine. C.r. hebd. Séanc. Acad. Sci., Paris, 252, 1515.

\section{EXPLANATION OF PLATE 1}

Longitudinal sections, $12 \mu$ thick, of the uterine lumen showing the position and development of the mouse blastocyst at various times on Days 4 and 5 of pregnancy.

FrG. 1. 10.00 hours, Day 4 of pregnancy. Three blastocysts lying adjacent in the middle of the uterine horn before spacing has occurred. $\times 210$.

Fig. 2. 10.00 hours, Day 4 of pregnancy. Four blastocysts dispersing along the uterine lumen at the commencement of spacing. $\times 80$

Fig. 3. 16.00 hours, Day 4 of pregnancy. A small round blastocyst lying free in the uterine cavity. $\times 210$.

Fig. 4. 20.00 hours, Day 4 of pregnancy. An early stage of blastocyst enlargement. $\times 210$. Fig. 5. 02.00 hours, Day 5 of pregnancy. Further enlargement occurring in a blastocyst early on Day $5 . \times 210$.

Fig. 6. 15.00 hours, Day 5 of pregnancy. A large, thin walled blastocyct recovered at the time when loose attachment was evident from recoveries of zygotes after flushing. $\times 210$. 
PLATE 1
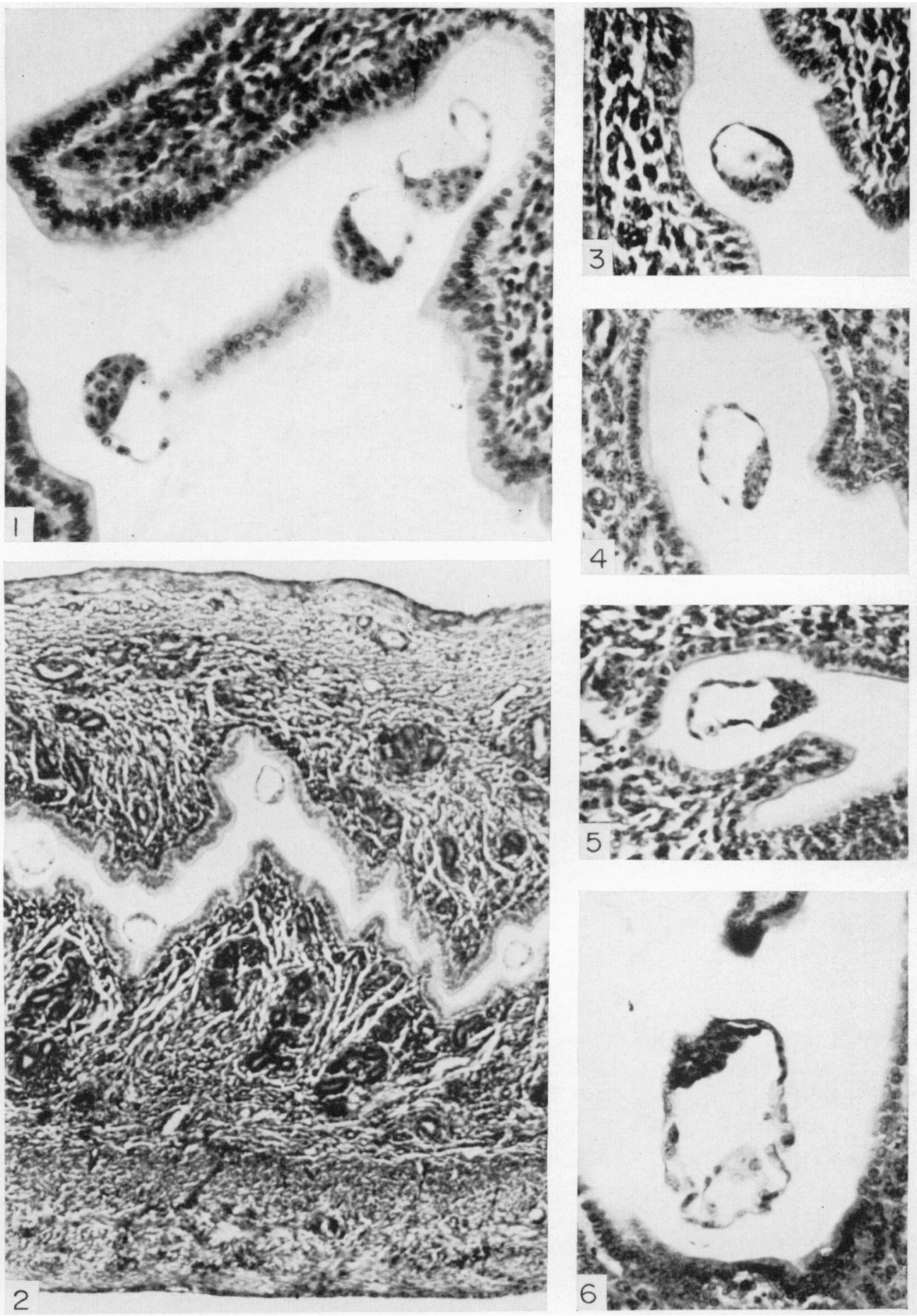